\title{
Sosialisasi Resiko Paparan Radiasi Gelombang Elektromagnetik yang dihasilkan oleh Smartphone terhadap Pertumbuhan Otak Anak
}

\author{
Nindha Ayu Berlianti ${ }^{1}$, Nur Hayati ${ }^{2}$, Noer Af'idah ${ }^{3}$, Oktaffi Arinna Manasikana ${ }^{4}$, \\ Andri Wahyu Wijayadi ${ }^{5}$ \\ Universitas Hasyim Asy'ari Jombang ${ }^{1,2,3,4,5}$ \\ nindhaayuberlianti@yahoo.com¹, nurhay.ht@gmail.com² ${ }^{2}$,noer_afidah1985@gmail.com³ \\ changemaker.salatiga@gmail.com ${ }^{4}$,diaandri@gmail.com ${ }^{5}$
}

\begin{abstract}
This community service program aimed to increase the knowledge and awareness of mothers in Sumbernongko Village, Ngusikan District, Jombang Regency about the importance of early education about the risks and dangers of electromagnetic waves exposed by smartphone signals (gadgets). The activities in this program were carried out by giving lectures, presenting interactive videos and question and answer. The first step was to provide education about what radiation is and its use in communication and the impacts that will occur in the short and long term. Then, it was followed by giving tips on reducing the use of gadgets. The target of this community service program was to make parents able to be wise and firm when limit ing the use of gadgets to their children and familiarize their children with activities outside or inside the home more because the role of parents in children's development is largely determined by their daily activities.
\end{abstract}

Keywords: radiation exposure; electromagnetic wave; gadget.

\begin{abstract}
Abstrak
Program pengabdian kepada masyarakat ini bertujuan untuk meningkatkan wawasan pengetahuan serta kesadaran para ibu-ibu di Desa Sumbernongko Kecamatan Ngusikan Kabupaten Jombang tentang pentingnya edukasi sejak dini tentang resiko dan bahaya gelombang elektromagnetik yang di paparkan oleh sinyal smartphone (gadget). Kegiatan dilakukan dengan memberikan ceramah, pemaparan video interaktif dan tanya jawab. Langkah awal yang dilakukan adalah memberikan edukasi tentang apa itu radiasi dan penggunaannya dalam komunikasi serta dampak yang akan terjadi dalam jangka pendek maupun jangka panjang, kemudian kiat-kiat mengurangi penggunaan gadget. Target dari kegiatan program pengabdian kepada masyarakat ini adalah agar para orang tua dapat dengan bijak dan tegas dalam membatasi penggunaan gadget pada anak dan lebih membiasakan anak untuk memperbanyak aktivitas diluar ataupun didalam rumah, karena peran orang tua dalam perkembangan anak sangat ditentukan dari kebiasaan yang dilakukan sehari-hari.
\end{abstract}

Kata Kunci: paparan radiasi; gelombang elektromagnetik; gadget. 


\section{A. PENDAHULUAN}

Kemajuan ilmu pengetahuan dan teknologi semakin canggih dan komplek. Perkembangan teknologi komunikasi yang semakin pesat ini ditandai dengan hadirnya berbagai media rumit seperti halnya gadget, smartphone, tablet dan lainnya. Kita sebagai manusia modern tidak mampu menepis perubahan yang terjadi akan tetapi kita dapat membatasi dampak negatif dari perkembangan yang terjadi. Menanggapi kondisi ini masyarakat harus bisa mengikuti perubahan dan perkembangan karena kebutuhan hidup yang semakin rumit.

Penggunaan gadget saat ini tidak mengenal usia, dari batita hingga lansia pun punya, bahaya gadget secara berlebih pun tidak begitu diperhatikan oleh beberapa kalangan, misalnya dengan memberikan anak gadget dianggap mampu meringankan pekerjaan orang tua. Sehingga menjadikan kebiasaan buruk yang terjadi pada saat ini. Perubahan kebiasaan tersebut menjadikan perubahan karakter pada anak yang ditandai dengan kurangnya cara bersosialisasi dengan masyarakat, lambat dalam perkembangan motorik dan perilaku pada anak (Chusna, 2017). Selain itu efek berlebih dalam penggunaan gadget menjadikan kurangnya manajemen emosional karena di sebabkan miskin interaksi dan komunikasi dengan lingkungan sekitar, sehingga anak menjadi sosok yang introvent dan tidak sabar (Suhana, 2018).

Faktanya radiasi gelombang yang dihasilkan dari penggunaan gadget dapat menimbulkan beberapa dampak dalam jangka pendek/jangka panjang. Dampak tersebut dapat berupa pusing, mual, stress, telinga berdenging, kerusakan kornea, insomnia, demam, muntah, mutasi genetika, gangguan sistem syaraf, kanker, gangguan sistem reproduksi hingga kematian, tergantung seberapa besar radiasi yang kita terima. Disamping itu juga dapat menyebabkan perubahan keseimbangan tubuh yang ditandai dengan berlebihnya kadar radikal bebas dalam sistem organ, sehingga mampu menurunkan kadar antioksidan protektif dan memicu terjadinya kerusakan sel jaringan yang tidak dapat dihindarkan (Victorya, 2015).

Variasi intensitas radiasi yang dikeluarkan dari gadget dapat merambat tanpa melalui medium perantara. Pengeluaran dan perambatan energi tersebut menembus ruang dalam bentuk gelombang elektromagnetik. Misalnya suara manusia dapat ditransfer sebagai gelombang radio atau mikro. Resiko terpapar gelombang elektomagnetik ini sangat besar, seperti yang sudah disampaikan diawal tentang dampak yang ditimbulkan. Maka dari itu mengingat pentingnya edukasi tentang bahaya dan dampak paparan radiasi gelombang elektromagnetik yang dihasilkan oleh sinyal dari gadget menjadikan salah satu alasan kami untuk memberikan sosialisasi kepada masyarakat khususnya para ibu di desa sumbernongko yang mayoritas para ibu-ibu di daerah tersebut bekerja, dengan harapan dapat memberikan pencerahan, motivasi serta masukan/tambahan informasi pada Ibuibu warga desa sumbernongko.

Tujuan Kegiatan PKM ini ialah: (1) Ibu-ibu warga Sumbernongko memperoleh pengetahuan mengenai radiasi dan penggunaanya dalam komunikasi; (2) Ibuibu warga Sumbernongko memperoleh sumber referensi baru mengenai dampak yang di timbulkan dari penggunaan radiasi gelombang elektromagnetik dalam komunikasi dan kiat-kiat mengurangi penggunaan gadget. 


\section{B. PELAKSAAAN DAN METODE}

Pelaksanakan program pengabdian ini, dilakukan secara mitra antara tim pengabdian dari dosen-dosen program studi pendidikan IPA UNHASY Jombang dengan perangkat desa dan ibu-ibu warga desa Sumbernongko Kecamatan Ngusikan Kabupaten Jombang (Mitra). Peran mitra adalah memberikan informasi tentang kendala yang dihadapi oleh masyarakat di desa Sumbernongko Kecamatan Ngusikan. Adapun permasalahan yang dihadapi yaitu minimnya edukasi tentang bahaya dan dampak paparan radiasi gelombang elektromagnetik (sinyal gadget) yang dapat menghambat perkembangan motorik dan tumbuh kembang anak.

Sasaran kegiatan pengabdian ini terdiri dari ibu-ibu warga desa Sumbernongko sekitar 25-30 orang. Lembaga Mitra yang bertanggungjawab pada kegiatan ini aparat desa Sumbernongko Kecamatan Ngusikan Kabupaten Jombang. Realita yang ditemukan, ternyata banyak masyarakat yaitu khususnya ibu-ibu warga desa Sumbernongko yang belum begitu memahami tentang dampak dan bahaya penggunaan smartphone (gadget) yang dikonsumsi secara berlebihan pada anak.

Metode kegiatan pengabdian dalam hal ini ialah: penyadaran/peningkatan pemahaman terhadap suatu masalah. Adapun Teknik pelaksanaan kegiatan PKM yakni: pemberikan ceramah, pemaparan video interaktif dan tanya jawab dengan pemaparan materi sosialisasi yaitu: Mengenal lebih jauh apa itu radiasi gelombang elektromegnetik; Penggunaan radiasi dalam komunikasi; Bahaya dibalik radiasi smartphone (gadget) terhadap pertumbuhan otak anak; Kiat-kiat mengurangi kecanduan gadget pada anak

\section{HASIL DAN PEMBAHASAN}

Kegiatan Pengabdian Masyarakat dengan tema "Sosialisasi Resiko Paparan Radiasi Gelombang Elektromagnetik yang dihasilkan oleh Smartphone Terhadap Pertumbuhan Otak Anak" pada tanggal 29 Februari-01 Maret 2020 dengan bertempat di balai Desa Sumbernongko telah terlaksana dengan baik. Acara berjalan lancar dengan dihadiri oleh para perangkat dan para ibu-ibu desa Sumbernongko. Acara dibuka oleh pembawa acara kemudian dilanjutkan sambutan dari ketua panitia dan sambutan oleh ibu Kepala desa Sumbernongko. Sesi berikutnya adalah pemberian materi. Adapun struktur materi sosialisasi sebagai berikut

Tabel 1. Susunan Materi Sosialisasi Kegiatan PKM

\begin{tabular}{llc}
\hline No & \multicolumn{1}{c}{ Materi Sosialisasi } & $\begin{array}{c}\text { Durasi } \\
\text { (Jam) }\end{array}$ \\
\hline 1 & $\begin{array}{l}\text { Mengenal lebih jauh apa } \\
\text { itu radiasi gelombang } \\
\text { elektromegnetik }\end{array}$ & 2 \\
\hline 2 & $\begin{array}{l}\text { Penggunaan radiasi } \\
\text { dalam komunikasi }\end{array}$ & 2 \\
\hline 3 & $\begin{array}{l}\text { Bahaya dibalik radiasi } \\
\text { smartphone (gadget) } \\
\text { terhadap pertumbuhan } \\
\text { otak anak }\end{array}$ & 2 \\
\hline 4 & $\begin{array}{l}\text { Diskusi dan Tanya } \\
\text { jawab }\end{array}$ \\
\hline 5 & $\begin{array}{l}\text { Penugasan kiat-kiat } \\
\text { mengurangi kecanduan } \\
\text { gadget pada anak }\end{array}$ & 26 \\
\hline 6 & Presentasi dan review \\
\hline
\end{tabular}

\section{Mengenal lebih jauh apa itu Radiasi Gelombang Elektromegnetik}

Radiasi merupakan energi yang ditransmisikan, dikeluarkan atau diabsorbsi dalam bentuk gelombang elektromagnetik. Gelombang ini dapat dikarakterisasi oleh beberapa hal, diantaranya: panjang 
gelombang, frekuensi, amplitudo, dan cepat rambatnya gelombang tersebut (Timor et al., 2016) Bila dilihat dari frekuensi yang digunakan, Panjang gelombang yang dipancarkan dari gadget berkisar $1 \mathrm{~m}-0.01 \mathrm{~m}$ (Idayati, 2011).

Pancaran radiasi tersebut akan memberikan dampak khususnya pada bagian telinga. Selain itu radiasi ini juga menimbulkan beberapa masalah lain seperti gangguan pada saraf otak yang menyebabkan menurunnya memori otak, bahkan tak banyak yang mengalami susah tidur. Akan tetapi daya dan frekuensi yang dirasakan dalam penggunaan komunikasi seluler nirkabel portabel hanya mampu memberikan gambaran dampak secara termal dan efek berkurangnya fungsi esensi otak tidak akan terjadi selama menggunakan ponsel biasa (Malik, 2020). Dampak radiasi sangat kompleks dan bervariatif, kemampuan energi radiasi yang dipancarkan mampu mengionisasi jaringan yang dituju. Spektrum gelnet ini diklasifikasikan menjadi 2 macam, yaitu radiasi pengion dengan frekuwensi diatas $106 \mathrm{~Hz}$ dan radiasi non-pengion dengan frekwensi dibawah $106 \mathrm{~Hz}$ (Dewi \& Wulan, 2015). Pemaparan gelombang yang tidak terkendali dari radiasi ionisasi dengan jumlah yang sangat besar, diketahui dapat memicu berbagai macam jenis penyakit dan bahkan kematian (Swamardika, 2019).

\section{Penggunaan Radiasi dalam Komunikasi}

Penemuan peralatan canggih dengan memanfaatkan energi elektromagnetik salah satunya adalah untuk kebutuhan komunikasi. Kemajuan IPTEK dalam dunia komunikasi yang mampu menciptakan berbagai kemudahan dalam mengakses informasi yang terkoneksi dengan orang lain yang tak asing lagi ialah dengan hadirnya telepon seluler (gadget). Gadget memanfaatkan gelombang radio. Gelombang inilah yang memancarkan radiasi dan berbagai macam dampak yang membahayakan bagi sistem organ manusia sehingga dari berbagai kalangan banyak muncul kontroversi tentang keamanan dalam menggunakan gadget (Hutauruk, 2012).

Dampak yang ditimbulkan akibat paparan elektromagnetik meliputi perubahan permeabilitas membran sel, perubahan komposisi pembentukan darah, perubahan pertukaran ion dalam jaringan syaraf dan perubahan tingkat kanker yang erat kaitannya dengan pembentukan enzim. Efek dan gangguan tersebut berpotensi merusak jika melampaui nilai ambang batas yang telah ditentukan yakni $10 \mathrm{~mW} / \mathrm{cm} 2$ masih termasuk dalam nilai batas aman (Swamardika, 2019). Gangguan biologis lainnya yang kerap dijumpai seperti: semakin mudah lelah, sakit kepala periodis, mudah marah dan cepat mengantuk.

\section{Bahaya dibalik Radiasi Smartphone (gadget) terhadap Pertumbuhan Otak Anak}

Dampak yang dihasilkan oleh radiasi elektromagnet dari gadget dibagi menjadi 2 yaitu (Agency, 2014): a) Efek fisiologi merupakan pengaruh yang dapat menyebabkan keluhan pada jaringan manusia seperti saluran pendengaran, tumor, gangguan pada jaringan mata sistem reproduksi, amnesia, kanker otak dan migrain (penyakit syaraf), dan b) Efek psikologi dapat menyebabkan munculnya stress dan ketaknyamanan karena penyinaran radiasi yang sering dan berulang.

Dampak subjektif lainnya yang sering dikeluhan dalam penggunaan gadget ialah sakit kepala. Keluhan ini disebabkan karena kelainan mata atau lainnya (Idayati, 2011). Seperti penyebab migrain yang di imbangi dengan keadaan posisi tubuh yang salah diduga menjadi salah satu penyebab 
ketegangan otot pada beberapa bagian tubuh seperti otot leher yang terhubung langsung ke bagian kepala sehingga ketegangan yang terjadi lama-kelamaan akan memicu migrain, disamping itu waktu yang lama ketika mengakses gadget dapat mengganggu sinyal di otak dan menyebabkan stress bahkan insomnia, hal ini disebabkan waktu kerja otak yang di paksa tetap aktif.

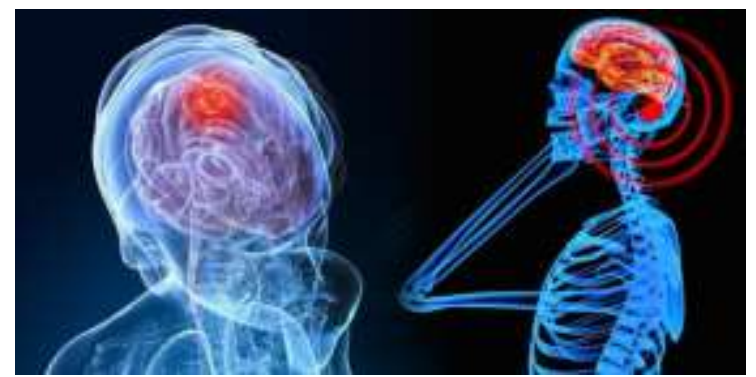

Gambar 1. Gambaran Paparan Radiasi Gadget pada Penderita Sakit Kepala

Penelitian yang berkaitan dengan radiasi smartphone terhadap perkembangan otak masih terus dilakukan untuk memperkuat kajian dan referensi ilmiah yang lebih sahih. Beberapa studi riset disampaikan bahwa, ketika melakukan panggilan dengan menggunakan telpon genggang tanpa headset (microphone), pengaruh paparan radiasi yang dipancarkan lebih besar terhadap kerja sistem otak dan jaringan syaraf. Keluhan-keluhan yang mucul lama-kelamaan akan menjadikan masalah yang serius yang perlu disikapi dan diwaspadai (Bahteran, 2013).

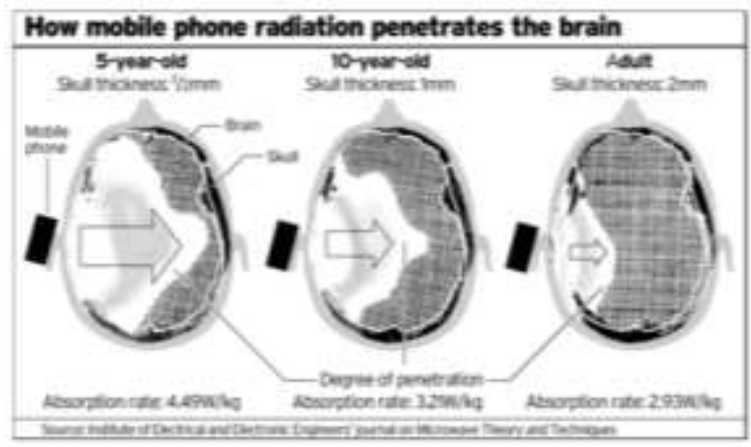

Gambar 2. Radiasi Gadget pada Otak Manusia
Berdasarkan pemaparan gambar tersebut terlihat bahwa radiasi yang dipancarkan oleh gadget sangat mudah menembus jaringan dan syaraf yang ada di otak. Hal ini disebabkan perkembangan tengkorak anak masih dalam proses pertumbuhan. Di beberapa negara seperti canada, anak usia dibawah 6 tahun dilarang memakai gadget. Remaja juga dibatasi penggunaannya $\leq 10 \mathrm{menit} / \mathrm{hari}$. Penelitian lain menyatakan bahwa dalam penggunaan ponsel mampu mempengaruhi hilangnya memori otak, karena struktur morfologi kepala anak yang masih kecil dengan kemampuan menghantarkan radiasi yang dipacarkan ke jaringan kepala lebih besar, sehingga tingkat penyerapan nya lebih cepat (Victorya, 2015).

Hasil penelitian mengungkapkan bahwa pemakain gadget mendominasi terhadap bahaya kanker otak. Hal ini dikarenakan dampak tersebut mempengaruhi beberapa kerja hormone yang dihasilkan oleh kelenjar pineal yang berperan dalam pemicu tumbuhnya tumor (Sumbayak, 2015).

\section{Kegiatan Diskusi dan Tanya Jawab}

Pada penyampaian ceramah dan kegiatan diskusi, ibu-ibu menyampaikan beberapa pertanyaan diantaranya: (1) Berapa lama efek samping atau keluhan yang dirasakan mulai muncul jika pada anak usia 1 tahun saja sudah mulai di kenalkan dengan gadget? (2) Apabila anak sudah tidak menggunaan gadget secara berlebihan, apakah keluhan yang dirasakan akan hilang? Penyampaian pertanyaan tersebut ditanggapi dengan antusias oleh para pemateri dan peserta pada kegiatan tersebut.

Tanggapan dari pertanyaan tersebut ialah (1) efek yang dirasakan mulai terasa secara perlahan sesuai dengan tingkat perkembangan otak balita (usia 0-5 tahun), karena pada masa ini bisa dikatakan periode 
terpenting dalam meningkatkan perkembangan anak secara optimal, jika pada tahap ini sudah dibiasakan dengan menggunakan gadget maka, akan memiliki impact yang dapat memicu terhambatnya perkembangan sistem otak seperti terlambat berbicara dan memahami bahasa. (2). Dalam hal ini, pengawasan orang tua sangat penting dalam memberikan batasan dan mengendalikan waktu bermain gadget untuk mengoptimalkan pertumbuhan dan perkembangan anak. Upaya ini dilakukan untuk mengurangi impact yang terjadi. Keluhan tersebut akan berangsur-angsur hilang dengan melakukan terapis yang dibantu oleh dokter spesialis dan psikiater anak.

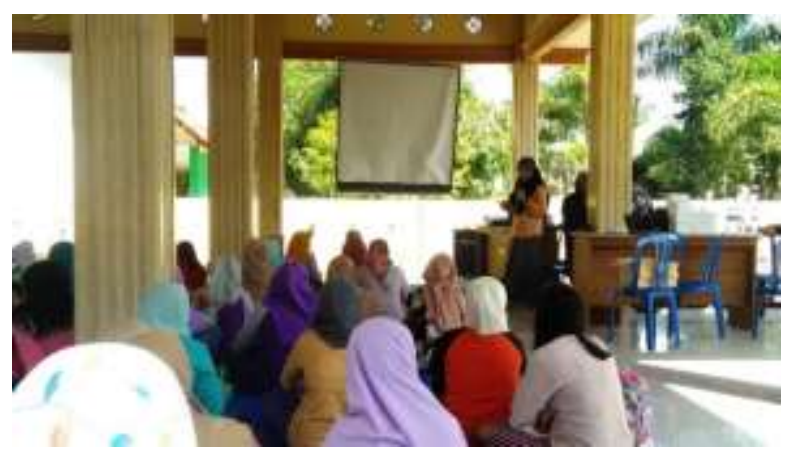

Gambar 3. Radiasi Gadget Pada Otak Manusia

\section{Kiat-kiat Mengurangi Kecanduan Smartphone (gadget) pada Anak}

Mengatasi ketergantungan gadget dan upaya pencegahanya, yaitu dengan cara menerapkan GMM (Gerakan Maghrib Mengaji), mengkondisikan anak dengan membangun sikap dan perilaku yang baik terhadap anak, mengatur lingkungan yang nyaman untuk anak dan lainnya, membuat kesepakatan antar orang tua dan anak, memantau kegiatan anak ketika mengakses gadget, Penggunaan fitur screen time yang dapat merekam aktivitas penggunaan gadget oleh anak selama beberapa hari.
Penggunaan beberapa aplikasi dengan pengawasan orang tua seperti Youtube Kids, Apple Education, Microsoft Education Center, Google Classroom (Pratikno \& Sumantri, 2020)

Kiat-kiat yang disampaikan tersebut memberikan kontribusi yang positif dan efektif akan keterlaksanaan kegiatan yang telah disampaikan pada sosialisasi resiko gelnet terhadap perkembangan otak anak, para ibu warga sumbernongko telah menerapkan kiat-kiat tersebut dalam kehidupan sehari-hari dengan memperhatikan penggunaan gadget pada anak. Disamping itu juga dilakukan kegiatan setiap akhir minggu yang dilaksanakan secara rutin sebagai bentuk penerapan "kegiatan hari tanpa gadget" dengan mengajak anak-anak datang ke balai desa untuk mengeksplor kreativitasnya dengan mengembangkan hobi yang mengasah keterampilan seperti melukis, mewarnai, bercerita dan lainnya.

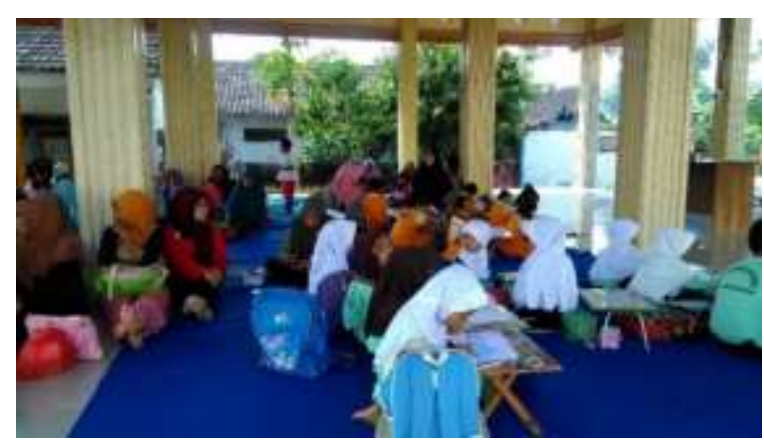

Gambar 4. Kegiatan melukis dan mewarnai oleh anak-anak

\section{PENUTUP}

\section{Simpulan}

Hasil yang dapat diambil dari kegiatan ini ialah (1) Kegiatan pengabdian ini direspon dengan sangat baik oleh para ibuibu warga Desa Sumbernongko Kecamatan 
Ngusikan Kabupaten Jombang. (2) Seluruh untaian program kegiatan yang dibawakan dapat dilaksanakan dengan baik dan terjadwal. (3) Membentuk kebiasaan dan kedisiplinan para orang tua dan lingkungan masyarakat dalam membatasi penggunaan smartphone pada anak perlu terus dipantau dan diawasi dalam penggunaannya sehingga dapat mengurangi dampak negatif yang ditimbulkan.

\section{Saran}

Ibu-ibu warga desa sumbernongko yang telah mengikuti serangkaian kegiatan sosialisasi diharapkan agar terus melaksanakan kegiatan rutin yang telah dilakukan setiap akhir pekan untuk membentuk kebiasaan baru dalam mengurangi penggunaan gadget pada anak, kemudian pada kegiatan selanjutnya dapat dibentuk panitia atau kader agar ada program kegiatan yang direncanakan. Misalnya pada jenis kegiatannya seperti diadakan perlombaan dan sebagainya.

\section{Ucapan Terimakasih}

Pada kesempatan yang baik ini, ucapan terimakasih disampaikan pada semua pihak yang telah membantu terlaksananya kegiatan pengabdian ini, khususnya untuk kepala desa dan masyarakat desa sumbernongko, ngusikan, jombang.

\section{E. DAFTAR PUSTAKA}

Agency, H. P. (2014). Documents of the NRPB. Exposure, 15(3).

Bahteran, R. (2013). Analisis Klasifikasi Ponsel (HP) Terhadap Paparan Radiasi Gelombang Elektromagnetik.

Chusna, P. A. (2017). Pengaruh Media Gadget Pada Perkembangan Karakter Anak. Dinamika Penelitian: Media
Komunikasi Sosial Keagamaan, 17(2), 315-330. https://eresources.perpusnas.go.id:2093/doi/abs /10.1142/S0192415X20500500.

Dewi, I. K., \& Wulan, A. J. (2015). Efek Paparan Gelombang Elektromagnetik Handphone terhadap Kadar Glukosa Darah Effects of Handphone Electromagnetic Wave Exposure on Blood Glucose Level. Jurnal Fakultas Kedokteran Universitas Lampung, 4(7), 31-38.

Hutauruk, S. (2012). Karakteristik Paparan Radiasi Ponsel pada Organ Kepala Manusia. Lembaga Penelitian Universitas HKBP Nommensen, 17(2), 15.

https://akademik.uhn.ac.id/portal/public _html/TEKNIK/ELEKTRO/Sindak_Hu tauruk/Karakteristik Paparan Radiasi Ponsel Pada Organ Kepala Manusia.pdf.

Idayati, R. (2011). Pengaruh Radiasi Handphone Terhadap Kesehatan. Jurnal Kedokteran Syiah Kuala, 11(2), 115120.

Malik, J. A. (2020). Effects of Electromagnetic Radiation of Mobile Phones on the Human Brain. In Government Degree College (Issue January, pp. 97-120). https://doi.org/10.4018/978-1-79982521-0.ch006.

Pratikno, A. S., \& Sumantri, S. (2020). Digital Parenting: Bagaimana Mencegah Kecanduan Gadget Pada Anak. Auladuna: Jurnal Prodi Pendidikan Guru Madrasah Ibtidaiyah, 2(1), 107-123. https://doi.org/10.36835/au.v2i1.301.

Suhana, M. (2018). Influence of Gadget Usage on Children's Social-Emotional Development. 169(Icece 2017), 224- 
227. https://doi.org/10.2991/icece17.2018.58.

Sumbayak, E. M. (2015). Dampak Gelombang Elektromagnetik Telepon Seluler terhadap Otak. Jurnal Kedokteran Universitas Kristen Krida Wacana.

Swamardika, I. B. A. (2019). Pengaruh Radiasi Gelombang Elektromagnetik Terhadap Kesehatan Manusia (Suatu Kajian Pustaka). Pengaruh Radiasi Gelombang Elektromagnetik Terhadap Kesehatan Manusia, 8(1), 1-4.

Timor, A. R., Andre, H., \& Hazmi, A. (2016). Analisis Gelombang Elektromagnetik dan Seismik yang Ditimbulkan oleh Gejala Gempa. Jurnal Nasional Teknik Elektro, $5(3)$ 315. https://doi.org/10.25077/jnte.v5n3.297. 2016.

Victorya, R. M. (2015). Effect of Handphone Electromagnetic Wave Exposure on Seminiferous Tubules. J Majority, 4(3), 96-100. 